\title{
Efektivitas Pembelajaran Kooperatif Dengan Permainan Dalam Matematika
}

\author{
Ni Ketut Erawati \\ IKIP PGRI Bali, Jl. Seroja Denpasar \\ e-mail: erawatiniketut294@gmail.com \\ Ni Made Suwarnisi \\ IKIP PGRI Bali, Jl. Seroja Denpasar \\ e-mail: nimadesuwarnisi47@gmail.com
}

\begin{abstract}
The purpose of this study was to determine the effectiveness of the application of the STAD cooperative learning model combined with ice breaking in mathematics subjects on motivation and learning outcomes of student. This research is a quasi-experimental study using the non equivalent design group design. This design uses two sample groups selected with random sampling and randomized classes are already available. This research was conducted at SMK N 4 Denpasar with a population of 10th grade students consisting of 10 classes, then two classes were selected as samples.Data collection using questionnaires and essay test. Data analysis uses $t$-test for the first hypothesis and the second hypothesis while the third hypothesis analysis uses MANOVA. The results of the research show that the motivation and learning outcomes between the experimental group and the comparison group differed significantly, where better results were obtained in the experimental group ie the group that applied STAD cooperative learning with ice breaking. The results of this study indicate that cooperative learning innovations especially the STAD type combined with ice breaking as a game or pause in mathematics learning provide effective results in achieving student learning outcomes and motivation at a better level.
\end{abstract}

Keywords: cooperative learning models, ice breaking, learning motivation, learning outcomes, STAD

\section{Pendahuluan}

Belajar matematika merupakan suatu syarat cukup untuk melanjutkan pendidikan ke jenjang berikutnya. Karena dengan belajar matematika, mengajarkan sesorang bernalar secara kritis, kreatif dan aktif. Oleh karena itu pelajaran matematika diajarkan di semua jenjang pendidikan (Slameto, 2015). Siswa SMK pun mendapat pelajaran matematika, meskipun porsinya berbeda dengan siswa SMA. Karakter siswa SMK adalah bukan hanya menerima teori yang abstrak melainkan langsung mengerjakan secara nyata, 
sehingga pada saat belajar matematika siswa tidak termotivasi untuk belajar karena belajar matematika hanya sesuatu yang dianggap tidak digunakan dalam kehidupan nyata. Oleh karena itu perlu dipilih model yang tepat untuk memfasilitasi siswa agar termotivasi belajar matematika dan memperoleh hasil belajar yang baik. Menurut Indah, dkk (2017) matematika merupakan ilmu yang mempelajari tentang bilangan, model, dan struktur yang terorganisasi, matematika juga membahas mengenai definisi, teorema, fakta, dan korelasi diantara ruang dan bentuk. Dengan konsep matematika tersebut seseorang dapat mengetahui bahwa dalam memecahkan masalah haruslah sistematis dan berproses.

Meskipun telah banyak dilakukan inovasi dalam pendidikan dan pembelajaran khususnya matematika, namun hasilnya belum memuaskan. Akibat nyata yang ditemui adalah hasil kemampuan matematika melalui TIMSS 2015 (Trends in International mathematics and Science Study) menunjukkan bahwa Indonesia mendapatkan peringkat 45 dari 50 negara yang mengikuti TIMSS dan masih dibawah rata-rata negara OECD (Organization for Economic Co-operation and Development) (Mullis, Martin, Foy, and Hooper, 2016). Hal ini dapat memberikan gambaran mengenai tingkat pemahaman dan penguasaan siswa terhadap mata pelajaran matematika masih dalam taraf kemampuan berpikir tingkat rendah. Harus diakui bahwa mutu pendidikan pada umumnya masih rendah, terlebih lagi mutu pendidikan matematika. Siswa tidak diberdayakan untuk berpikir, kemampuan yang dikembangkan hanyalah kemampuan menghafal dan kemampuan kognitif kelas rendah.

Bercermin kondisi tersebut, pembelajaran matematika di sekolah perlu diciptakan lingkungan belajar yang menyenangkan. Di lain pihak, perspektif belajar yang baru menyatakan bahwa belajar adalah proses mengkonstruksi pengetahuan. Oleh karena itu, guru dituntut untuk memahami dan mampu menerapkan berbagai model pembelajaran yang sesuai dengan kekhasan materi dan karakteristik siswa sehingga dapat memfasilitasi aktivitas siswa dalam belajar. Salah satu model pembelajaran yang dapat menjadi pilihan adalah model pembelajaran kooperatif tipe Student Team Achievement Division (STAD) yang mengutamakan kerja sama diantara siswa, diskusi dan berinteraksi dalam kelompok sehingga mampu membuat siswa aktif selama proses pembelajaran (Farida, 2014).

Model Pembelajaran Kooperatif STAD dapat menciptakan iklim dan atmosfer yang aktif dan interaktif dalam pembelajaran sebagaimana tercermin dalam pola interaksi siswa dalam kelompok, dan diskusi antara guru dan siswa (Munawaroh, 2013). Model pembelajaran kooperatif tipe STAD merupakan salah satu tipe kooperatif yang menekankan pada adanya aktivitas dan interaksi diantara siswa untuk saling memotivasi dan saling bekerjasama dalam menguasai materi pelajaran guna mencapai prestasi maksimal (Isjoni, 2010). Oleh karena itu iklim ini menumbuhkan kebersamaan dan keterbukaan selama pembelajaran, sehingga rasa nyaman pasti timbul saat belajar karena 
tidak adanya keterpaksaan atau tekanan dalam menyampaikan ide atau permasalahan yang dialami karena berdiskusi dengan teman sebaya.

Supaya pembelajaran tidak monoton hanya dalam kegiatan kelompok maka perlu dipadukan dengan hal yang menarik dan menyenangkan bagi siswa, salah satunya dengan ice breaking. Siswa akan lebih dapat menerima materi pelajaran jika suasana tidak tegang, santai, nyaman, dan lebih bersahabat (Sunarto,2012). Istilah ice breaking berasal dari dua kata asing, yaitu ice yang berarti es yang memiliki sifat kaku, dingin, dan keras, sedangkan breaking berarti memecahkan. Arti harfiah ice-breaking adalah pemecah es. Jadi, ice breaking bisa diartikan sebagai usaha untuk memecahan atau mencairkan suasana yang kaku seperti es agar menjadi lebih nyaman mengalir dan santai. Ice breaking merupakan suatu aktivitas di sela-sela waktu pembelajaran baik awal, tengah maupun akhir berupa permainan, humor, pencerahan, atau aktivitas lainnya yang dapat mencairkan suasana, sehingga siswa tidak tegang dan bosan (Faruqi, 2016). Hasil penelitian Harsyad, dkk (2016) menunjukkan bahwa menggunakan Ice Breaking dapat menciptakan pembelajaran yang kreatif agar siswa tidak merasa bosan dalam mengikuti pembelajaran matematika sehingga tercipta suasana belajar yang menyenangkan dan dapat membuat minat belajar peserta didik meningkat.

Suasana belajar yang menyenangkan tentunya dapat menumbuhkan motivasi diri siswa untuk lebih giat belajar. Motivasi mengandung keinginan yang mengaktifkan, menggerakkan, menyalurkan dan mengarahkan sikap dan perilaku individu belajar (Jumarniati, 2016). Menurut Uno (2012), hakikat motivasi belajar adalah dorongan internal dan eksternal pada siswa-siswa yang sedang belajar untuk mengadakan perubahan tingkah laku, pada umumnya dengan bebarapa indikator atau unsur yang mendukung. Indikator motivasi belajar dapat diklasifikasikan sebagai berikut: (a) hasrat dan keinginan berhasil; (b) dorongan dan kebutuhan dalam belajar; (c) harapan dan citacita masa depan; (d) penghargaan dalam belajar; (e) kegiatan yang menarik dalam belajar; (f) lingkungan belajar yang kondusif, sehingga memungkinkan seseorang siswa dapat belajar dengan baik.

Oleh karena itu, menggunakan model pembelajaran kooperatif STAD dipadukan dengan ice breaking pada mata pelajaran matematika dapat menjadi pilihan yang tepat untuk membangkitkan motivasi dan berimbas pada hasil belajar siswa. Pada penelitian ini diselidiki efektivitas penerapan model pembelajaran kooperatif STAD dikombinasikan dengan ice breaking pada pembelajaran matematika. Efektivitas tersebut dilihat dari perbedaan motivasi dan hasil belajar antara siswa yang diterapkan pembelajaran kooperatif berpadukan ice breaking dibanding siswa yang diterapkan pembelajaran konvensional. 


\section{Metode Penelitian}

Penelitian ini adalah penelitian eksperimental semu dengan desain kelompok non ekivalen. Desain ini menggunakan dua kelompok sampel yang dipilih secara acak. Teknik acak yang digunakan adalah cluster random sampling yang dilanjutkan dengan simple random sampling. Penelitian ini dilakukan di SMK N 4 Denpasar dengan populasi siswa kelas X yang terdiri dari 10 kelas, kemudian dipilih dua kelas sebagai sampel. Diperoleh kelompok eksperimen yaitu kelas X Tata Boga 4 berjumlah 36 siswa dan kelompok kontrol yaitu X Tata Boga 1 berjumlah 36 siswa. Variabel bebas adalah model pembelajaran dan variabel tak bebas adalah motivasi dan hasil belajar. Pengumpulan data menggunakan angket motivasi belajar dan tes esai untuk mengetahui data hasil belajar yang telah divalidasi. Setelah data diperoleh dan terkumpul kemudian dianalisis menggunakan uji-t untuk hipotesis I dan II, uji MANOVA untuk hipotesis III namun sebelumnya harus memenuhi beberapa uji prasyarat yaitu uji normalitas, uji homogenitas, uji multikolinearitas, uji homogenitas matriks varians/kovarians variabel terikat.

Adapun langkah-langkah pembelajaran kooperatif tipe STAD menurut Slavin (dalam Utami, 2015) diantaranya: 1) Pembagian kelompok dengan cara membagi siswa menjadi beberapa kelompok yang setiap kelompoknya terdiri dari 4-5 siswa yang memprioritaskan heterogenitas (keragaman) kelas dalam prestasi akademik, gender/jenis kelamin, ras atau etnik; 2) Penyampaian materi dari guru yaitu proses pembelajaran dalam kegiatan presentasi, guru menggunakan media, demonstrasi, masalah nyata yang terjadi dalam kehidupan sehari-hari dan menyampaikan tugas ataupun pekerjaan yang harus dikerjakan disertai cara-cara untuk mengerjakannya; 3) Kegiatan belajar dalam tim (diskusi kelompok) akan terlaksana ketika siswa belajar dalam kelompok yang telah dibentuk dan guru menyiapkan lembar kerja sebagai pedoman untuk melaksanakan kerja kelompok sehingga semua anggota menguasai dan memberikan kontribusi hasil pemikiran untuk dipresentasikan. Selama kelompok bekerja, guru melakukan pengamatan, memberikan bimbingan, dorongan dan bantuan apabila diperlukan oleh siswa; 4) Guru mengevaluasi hasil belajar melalui pemberian kuis atau pertanyaan tentang materi yang dipelajari dan melakukan penilaian terhadap presentasi yang dilaksanakan di akhir pertemuan; 5)Setelah proses pembelajaran selesai, salah satu anggota dari masing-masing kelompok dapat menyampaikan kesimpulan; 6) Penghargaan, misalnya apabila suatu tim telah mengumpulkan skor paling banyak di kelas tersebut maka mereka mendapatkan penghargaan, penghargaan tidak harus berupa materi, tetapi dapat diberikan dalam bentuk nilai tambahan atau hal non materi lain. 


\section{Hasil dan Pembahasan}

Data penelitian ini terdiri atas data motivasi belajar matematika dan hasil belajar matematika dari kedua kelas sampel, yang disajikan pada Tabel 1. Data kelompok eksperimen dilambangkan dengan KE sedangkan data kelompok pembanding/kontrol disimbolkan dengan KK.

Tabel 1. Rekapitulasi Hasil Perhitungan Data Motivasi dan Hasil Belajar

\begin{tabular}{|l|l|l|l|l|}
\hline \multirow{2}{*}{ Data Statistik } & \multicolumn{2}{c|}{ Motivasi Belajar Siswa } & \multicolumn{2}{c|}{ Hasil Belajar Siswa } \\
\cline { 2 - 5 } & \multicolumn{1}{|c|}{ KE } & \multicolumn{1}{c|}{ KK } & \multicolumn{1}{c|}{ KE } & \multicolumn{1}{c|}{ KK } \\
\hline Rata-rata & 73,75 & 62,17 & 68,39 & 53,06 \\
\hline Median & 73,86 & 61,95 & 68,72 & 52,5 \\
\hline Modus & 75 & 62 & 69 & 50 \\
\hline Skor maksimum & 93 & 85 & 78 & 67 \\
\hline Skor minimum & 40 & 44 & 55 & 44 \\
\hline
\end{tabular}

Semua data yang terkumpul diolah dengan bantuan SPSS 22.0 for windows. Sebelum uji hipotesis dilakukan uji prasyarat yaitu uji normalitas, uji homogenitas, uji multikolinearitas, uji homogenitas matriks varians/kovarians variabel terikat. Berdasarkan hasil uji normalitas menunjukkan nilai Sig. yang lebih dari 0,05, berarti sebaran data berasal dari populasi yang berdistribusi normal. Uji prasyarat kedua yaitu uji homogenitas varians yang dilakukan untuk meyakinkan bahwa perbedaan yang diperoleh dari hasil uji hipotesis berasal dari perbedaan kelompok, bukan disebabkan oleh perbedaan didalam kelompok. Berdasarkan hasil uji diperoleh nilai Sig. lebih dari 0,05, berarti varians dalam kelompok tersebut merupakan varians yang homogen. Uji prasyarat ketiga yaitu uji multikolinearitas dilakukan untuk mengetahui ada tidaknya hubungan yang signifikan antar variabel bebas. Berdasarkan output SPSS 22.0 for windows, nilai VIF dari variabel motivasi belajar matematika dan variabel hasil belajar matematika sebesar 1,171, sehingga tolerance 0,854 . Karena VIF bernilai $1,171<10$ dan tolerance bernilai $0.854>0,1$ maka variabel bebas tidak mengalami multikolinearitas dan tidak harus digugurkan. Uji prasyarat keempat adalah uji matriks varians/kovarians variabel terikat secara bersamaan. Uji homogenitas matriks varians/kovarians dilihat dari hasil uji Box M. Berdasarkan output SPSS 22.0 for windows diperoleh nilai 0,062 > 0,05, berarti variabel terikat motivasi belajar dan hasil belajar mempunyai matriks varian-kovarian yang sama pada kelompok variabel bebas.

Semua uji prasyarat telah terpenuhi, selanjutnya dilakukan uji hipotesis. Berdasarkan output SPSS 22.0 for windows untuk hipotesis pertama menggunakan uji-t diperoleh nilai pada Sig. (2-tailed) sebesar 0,001<0,05, yang berarti terdapat perbedaan 
motivasi belajar siswa antara yang mengikuti model pembelajaran STAD dipadukan ice breaking dengan siswa yang mengikuti model pembelajaran konvensional. Berdasarkan output SPSS 22.0 for windows untuk hipotesis kedua menggunakan uji-t diperoleh nilai pada Sig. (2-tailed) sebesar 0,001 < 0,05, yang berarti terdapat perbedaan hasil belajar siswa antara yang mengikuti model pembelajaran STAD dipadukan ice breaking dengan siswa yang mengikuti model pembelajaran konvensional. Hasil pengujian hipotesis ketiga didasarkan pada Pillai's Trace, Wilks Lambda, Hotelling's Trace, dan Roy's Largest Root. Pada pengujian tersebut, diperoleh pada kolom sig. angka-angka sebesar 0,001 . Ternyata nilai sig $<0,05$, yang berarti, yang berarti terdapat perbedaan secara simultan motivasi dan hasil belajar matematika siswa antara yang mengikuti model pembelajaran STAD dipadukan ice breaking dengan siswa yang mengikuti model pembelajaran konvensional.

Hasil penelitian ini menunjukkan bahwa terdapat perbedaan secara parsial dan simultan motivasi dan hasil belajar matematika siswa antara yang mengikuti model pembelajaran STAD dipadukan ice breaking dengan siswa yang mengikuti model pembelajaran konvensional. Perbedaan secara parsial yaitu perbedaan secara signifikan dari masing-masing variabel terikat yang diukur dan dianalisis secara terpisah. Hasil analisis secara parsial menunjukkan bahwa hasil belajar antara kedua kelas sampel berbeda secara signifikan, dan motivasi belajar siswa antara kedua kelas sampel juga berbeda secara signifikan. Sedangkan perbedaan secara simultan yaitu perbedaan yang signifikan secara bersama-sama antara kedua variabe terikat yang diukur yaitu antara hasil belajar dan motivasi siswa.

Pembelajaran konvensional yang dimaksud dalam penelitian ini adalah pembelajaran yang telah biasa dilakukan oleh guru kelas di sekolah, yaitu memberikan penjelasan materi, contoh dan latihan soal baik individu ataupun kelompok tanpa lembar kerja. Sedangkan pada pembelajaran kooperatif STAD dalam diskusi kelompok disediakan lembar kerja dan control tetap dari guru, dan beberapa kegiatan ice breaking yang dilakukan adalah melakukan pijat pundak, pesan berbisik, hitung sederhana secara cepat, bertepuk tangan, serta tebak kata. Banyak permainan ice breaking lainnya yang bisa dilakukan namun tetap melihat waktu yang tersedia. Disinilah peran guru sebagai kontrol utama, pengatur dan pengarah jalannya permainan dan pembelajaran.

Hasil penelitian ini tidak terlepas dari langkah-langkah dalam pembelajaran kooperatif tipe STAD itu sendiri ditambah dengan kegiatan ice breaking diberikan ditengah-tengah proses pembelajaran berlangsung untuk membuat suasana yang sebelumnya sudah mencapai titik jenuh menjadi lebih menyenangkan dan dapat mengikuti proses pelajaran selanjutnya dengan lebih semangat. Langkah-langkah pembelajaran tersebut memberikan kelebihan tersendiri dalam STAD diantaranya meningkatkan kerja sama, meningkatkan harga diri yang dapat memperbaiki sikap ilmiah 
terhadap matematika, memperbaiki kehadiran peserta didik, konflik pribadi menjadi berkurang, adanya penghargaan membuat motivasi belajar siswa menjadi lebih besar, serta akan membuat hasil belajar lebih tinggi.

Hasil penelitian ini didukung oleh hasil penelitian Fitriani (2017) yang menunjukkan rata-rata hasil belajar matematika yang dibelajarkan dengan model pembelajaran kooperatif dipadukan ice breaking memberikan peningkatan yang signifikan, yaitu 82,30 dari yang awalnya 73,30. Selain itu hasil penelitian Sutrisno, Mardiyana, Usodo (2013) menyatakan model pembelajaran kooperatif tipe STAD dengan pendekatan SAVI menghasilkan motivasi belajar terbaik yang dibandingkan dengan model pembelajaran kooperatif tipe TPS. Hasil penelitian Ardiani, Gunarhadi, dan Riyadi (2018) juga menyatakan pembelajaran kooperatif STAD dengan pendekatan RME memberikan hasil belajar yang lebih baik daripada pembelajaran kooperatif TPS dengan pendekatan RME. Hal yang perlu diperhatikan dalam pembelajaran adalah ketetapan motivasi belajar yang ada dalam diri siswa, sehingga pembelajaran tetap efisien bagi siswa.

\section{Kesimpulan dan Saran}

Model pembelajaran STAD dipadukan dengan ice breaking sebagai permainan di sela-sela pembelajaran efektif dalam pembelajaran matematika. Efektivitas ini dilihat dari motivasi dan hasil belajar matematika yang lebih baik pada siswa yang mengikuti model pembelajaran STAD dipadukan ice breaking dibandingkan dengan siswa yang mengikuti model pembelajaran konvensional. Oleh karena itu penerapan STAD adalah salah satu alternatif dari berbagai model pembelajaran yang bisa digunakan dalam pembelajaran matematika, sehingga menerapkan berbagai model dan metode secara dinamis diperlukan dalam pengelolaan kelas yang disesuaikan dengan kondisi dan lingkungan sekolah. Selain menerapkan model yang tepat dan dinamis, melakukan ice breaking di sela-sela pembelajaran juga menjadi cara yang efektif dalam mengatasi kejenuhan siswa dalam belajar dan mengembalikan konsentrasi untuk belajar.

Berdasarkan simpulan tersebut dapat disampaikan saran kepada guru ataupun tenaga kependidikan lainnya untuk menggunakan model pembelajaran STAD sebagai alternatif dalam pembelajaran, namun tetap tidak monoton dengan satu model saja. Selain itu model apapun yang dipilih dalam pembelajaran, sangat penting melakukan relaksasi khususnya di tengah proses pembelajaran matematika yang melelahkan untuk menghilangkan kejenuhan siswa dengan permainan (ice breaking) dengan tetap memperhatikan waktu yang tersedia dan tujuan pembelajaran yang harus dicapai. 


\section{Daftar Pustaka}

[1] Ardiyani, S.M., Gunarhadi, and Riyadi. 2018. Realistic Mathematics Education in Cooperative Learning Viewed from Learning Activity. Journal on Mathematics Education 9(2), p. 301-31.

[2] Farida, N. 2014. Eksperimentaso Model Pembelajaran Kooperatif Tipe Student Teams Achievement Divisions (Stad) Menggunakan Metode Pemecahan Masalah Ditinjau dari Sikap Kreatif Peserta Didik. Aksioma 3(1).

[3] Faruqi, Al. 2016. Meningkatkan Daya Serap Siswa Pada Pembelajaran Geometri Menggunakan Ice Breaking. Jurnal Riset Pendidikan 2(1).

[4] Fitriani, NL., Wiarta, IW., dan Suniasih, NW. 2017. Pengaruh Model Pembelajaran Realistik Setting Kooperatif (RESIK) Dipadukan Dengan Ice Breaking Terhadap Hasil Belajar Matematika. Mimbar PGSD Undiksha 5(2).

[5] Harsyad, F., Afif, A., Abrar, A I P. 2016. Studi Komparasi Penggunaan Ice Breaking Dan Brain Gym Terhadap Minat Belajar Matematika Siswa Kelas Vii Smp Negeri 21 Makassar. MaPan : Jurnal Matematika dan Pembelajaran $4(2)$.

[6] Indah, L.N., Harahap, E., Farid, H.B., Darmawan, D. 2017. Pembelajaran Matematika Geometri Secara Realistis Dengan GeoGebra. Jurnal Matematika UNISBA 16(2).

[7] Isjoni. 2010. Cooperative Learning. Alfabeta, Bandung.

[8] Jumarniati. 2016. Pengaruh Motivasi Terhadap Hasil Belajar Matematika Siswa Kelas X Sman Di Kecamatan Biringkanaya. Prosiding Seminar Nasional 2(1).

[9] Mullis, I.V.S., Martin, M.O., Foy, P., Hooper. M. 2016. TIMSS 2015 International Results in Mathematics. IEA, Boston College.

[10] Munawaroh. 2013. The Effect of Type Stad Cooperative Learning Model, the Way of Learning, And Learning Motivation toward Enterpreneurial Attitudes. IOSR JRME 3(5), p. 38-44.

[11] Slameto. 2015. Belajar \& Faktor-Faktor yang Mempengaruhi. Rineka Cipta, Jakarta.

[12] Sunarto. 2012. Ice Breaker dalam Pembelajaran Aktif. Cakrawala Media, Surakarta.

[13] Sutrisno, Mardiyana, dan Usodo, B. 2013. Eksperimentasi Model Pembelajaran Kooperatif Tipe Stad Dan Tps Dengan Pendekatan Savi Terhadap Prestasi Dan Motivasi Belajar Ditinjau Dari Gaya Belajar Siswa. Jurnal Pembelajaran Matematika 1(7), p. 186-199.

[14] Uno, Hamzah. 2012. Teori Motivasi \& Pengukurannya. Bumi Aksara, Jakarta. 
Jurnal Matematika Vol. 9, No.2, Desember 2019, pp. 85-93

ISSN: $1693-1394$

Article DOI: 10.24843/JMAT.2019.v09.i02.p114

[15] Utami, S. 2015. Peningkatan Hasil Belajar melalui Pembelajaran Kooperatif Tipe STAD pada Pembelajaran Dasar Sinyal Video. JPTK 22(4), p. 424-431. 